\title{
Roça-de-toco: uso de recursos florestais e dinâmica da paisagem rural no litoral de Santa Catarina
}

\author{
Slash-and-burn agriculture: use of forest resources and dynamics of rural landscape in \\ Santa Catarina State, Brazil
}

\author{
Alexandre Siminski ${ }^{\mathrm{I}}$ Alfredo Celso Fantini ${ }^{\mathrm{II}}$
}

\section{RESUMO}

Os fragmentos florestais nas pequenas propriedades agrícolas de Santa Catarina fazem parte de um ciclo de cultivo de espécies anuais, através da agricultura de pousio (roça-detoco). Neste estudo, procurou-se analisar o sistema de cultivo praticado pelos agricultores do município de São Pedro de Alcântara, litoral de Santa Catarina, utilizando a abordagem qualitativa. Como resultados, observou-se que em $65 \%$ das propriedades houve redução da área de cultivo nos últimos 10 anos, o tempo de repouso foi reduzido e as roças passaram a ser menos itinerantes. As restrições ao uso dos recursos florestais têm promovido alterações na composição da paisagem das propriedades agrícolas da região de estudo, onde se constata uma diminuição das áreas destinadas à agricultura de pousio e um aumento crescente das áreas com formações florestais secundárias, além do aumento da proporção de formações mais avançadas no processo de sucessão natural. Entretanto, uma simulação do uso da terra revelou que é possível, do ponto de vista da disponibilidade de áreas ao longo do tempo, a continuidade do sistema de pousio, principalmente quando este destina-se à subsistência.

Palavras-chave: sucessão florestal, formações florestais secundárias, Mata Atlântica.

\section{ABSTRACT}

The secondary forests in the small farms of Santa Catarina State are traditionally used as a component of the slash-and-burn agriculture. The purpose of this study was to analyze the agricultural system in the municipality of São Pedro de Alcântara, on the coast zone of the State, using the qualitative research approach. The results showed that there was a reduction of the cultivated area in 65\% of the farms in the last 10 years, the fallow period was reduced, and the rotation time of each field plot was shortened. The restrictions imposed by regulations on forest resources use have contributed to a change in the

\begin{abstract}
composition of the landscape of the study area, where a shrinkage of the area used for traditional agriculture in favor of a larger area of with secondary forests is evident. However, a simulation of the field plots rotation revealed that, from the point of view of the land availability, the continuity of the slashand-burn agricultural system is still possible in the long run, especially under the subsistence farming.
\end{abstract}

Key words: forest succession, secondary forest, Brazilian Mata Atlantica.

\section{INTRODUÇÃO}

Avaliações da cobertura florestal nativa do Estado Santa Catarina apontam que restam cerca de 18\% da área original do domínio da Mata Atlântica (FUNDAÇÃO SOS MATA ATLÂNTICA \& INPE, 2000), em sua grande maioria na forma de fragmentos cobertos por formações florestais secundárias em diferentes estádios sucessionais, resultantes do processo de revegetação natural observado após o abandono das áreas onde eram desenvolvidas atividades agrícolas (QUEIROZ, 1994).

O sistema de cultivo utilizado por pequenos agricultores, chamado de pousio, roça-de-toco ou coivara, constitui uma tradição milenar da maioria das populações indígenas, sendo assimilada pelas populações remanescentes de processos de colonização (ADAMS, 2000; OLIVEIRA, 2002). Esse modelo é descrito por diversos autores e ocorre de modo semelhante em diferentes partes do mundo,

\footnotetext{
INúcleo de Pesquisas em Florestas Tropicais, Pós-graduação em Recursos Genéticos Vegetais, Universidade Federal de Santa Catarina (UFSC). Rod. Admar Gonzaga 1346, Itacorubi, 88034-001, Florianópolis, SC, Brasil. E-mail: alesiminski@yahoo.com.br. IIDepartamento de Fitotecnia, Pós-graduação em Recursos Genéticos Vegetais/Universidade Federal de Santa Catarina, UFSC Projeto Formações Florestais da Mata Atlântica. E-mail: afantini@cca.ufsc.br.
} 
sendo particularmente comum na zona das florestas tropicais e subtropicais. Exemplos de estudos de caso sobre os sistemas utilizados e sua implicações podem ser encontrados em ULH (1987), SALDARRIAGA et al. (1998), ADAMS (2000); COOMER et al. (2000), PERONI \& MARTINS (2000), MARTINS (2001) e OLIVEIRA (2002). O sistema é baseado na derrubada e queima da vegetação, seguindo-se um período de cultivo e, após o declínio da fertilidade do solo, um período de pousio para restauração da fertilidade.

Em grande parte do Estado de Santa Catarina, a roça-de-toco era o sistema predominante de cultivo da terra nas pequenas propriedade rurais. Esse uso da terra, entretanto, foi praticamente inviabilizado após a publicação do Decreto Lei 750 de 1993, que prevê que somente vegetação em estádio inicial de regeneração pode ser suprimida para fins agrícolas. Nesse estádio, como definido pelas resoluções 10/1993 e 04/1994, a vegetação apresenta biomassa insuficiente para fornecer a quantidade de nutrientes necessária para os anos de cultivo seguintes.

Estas resoluções foram publicadas sem estudos básicos prévios que lhes dessem suporte. Os produtores rurais, por sua vez, dizem estar fortemente prejudicados, alegando que essas foram responsáveis pela intensificação do processo de êxodo rural, uma vez que comprometeram a continuidade do sistema produtivo da região (SIMINSKI, 2004).

Neste trabalho, objetivou-se avaliar a prática do pousio agrícola, enquanto sistema produtivo integrante e transformador da paisagem onde está inserida. Compõe este objetivo a avaliação do sistema enquanto prática agrícola capaz de promover renda às propriedades da região, ao mesmo tempo em que integra um conjunto de estratégias que visam a atender as necessidades das populações envolvidas e a crescente necessidade de conservação dos escassos remanescentes da Mata Atlântica.

\section{MATERIAL E MÉTODOS}

Local de estudo

O município de São Pedro de Alcântara está localizado a 50km de Florianópolis, no litoral de Santa Catarina, onde residem 3.142 habitantes, dos quais 84\% na área rural. A estrutura fundiária caracteriza-se por pequenas propriedades com até 50 hectares (87\%), onde, na maioria dos casos, a agricultura deixou de ser a principal fonte de renda nos anos mais recentes (PMSPA, 2003).

O clima da região é classificado como Cfa, mesotérmico úmido com verão quente definido. A temperatura média anual é de $20^{\circ} \mathrm{C}$, sendo a média de temperatura do mês mais quente $25^{\circ} \mathrm{C}$ (janeiro) e a temperatura do mês mais frio $16^{\circ} \mathrm{C}$. A precipitação anual na região é de $1.390 \mathrm{~mm}$, bem distribuída durante o ano (IDE et al., 1980). O solo predominante da região é o Argissolo Vermelho Amarelo Distrófico típico, anteriormente denominado Podzólico Vermelho Amarelo Distrófico (EMBRAPA, 1999). O relevo da região é fortemente ondulado, com altitude média de 300m (SANTACATARINA, 1973).

A vegetação original do local, segundo KLEIN et al. (1986) e VELOSO et al. (1991), é característica de Floresta Ombrófila Densa, tendo sofrido exploração mais intensiva na década de 50 e atualmente se encontra predominantemente em estádio avançado de regeneração da vegetação, segundo a definição proposta pela Resolução n.04/1994 do CONAMA. As áreas utilizadas pela agricultura nos anos mais recentes encontram-se cobertas por vegetação secundária em diferentes estádios sucessionais.

\section{Métodos}

Foram realizadas entrevistas semiestruturadas junto aos agricultores do município, para levantar o histórico do uso da terra nas propriedades (ano em que o talhão foi deixado em pousio; duração do período de cultivo; culturas empregadas; práticas culturais adotadas, observações empíricas sobre os cultivos; entre outras). Os agricultores também participaram da elaboração do croqui das propriedades, realizado durante a entrevista, procurando identificar e caracterizar o mosaico das formações florestais e demais usos do solo.

As formações florestais foram classificadas como capoeirinha, capoeira, capoeirão e estádio arbóreo avançado, conforme a caracterização fitofisionômica do estádio de regeneração em que se encontravam (SIMINSKI, 2004, adaptada de KLEIN, 1980, em que: os estádios sucessionais capoeirinha, capoeira e capoeirão correspondem às denominações, respectivamente, Baccharisetum, Myrsinietum e Miconietum).

Na seleção dos agricultores, utilizou-se a técnica de amostragem intencional, que privilegia os sujeitos sociais que detêm os atributos que o investigador pretende conhecer (MINAYO, 1993). Colaboraram nessa identificação os agentes de extensão rural e da prefeitura municipal, selecionando os agricultores que possuíam em suas propriedades formações florestais secundárias em diferentes estádios de sucessão, resultantes do sistema de agricultura de pousio. Foram entrevistados os 
agricultores proprietários de 31 estabelecimentos agrícolas, distribuídos por todo o município.

Análise dos dados

Para a apresentação dos resultados, procurou-se analisar e interpretar o conteúdo das entrevistas realizadas com os agricultores, relacionando-o com o referencial teórico pesquisado e a visão do pesquisador. Com o objetivo de minimizar e identificar as possíveis diferenças existentes na ocupação da terra em relação à área total das propriedades, estas foram agrupadas em três categorias: até 20 hectares, entre 20 e 50 hectares e maiores que 50 hectares.

\section{RESULTADOS E DISCUSSÃO}

O sistema de agricultura de pousio na região

Todos os agricultores entrevistados praticavam a agricultura de pousio (roça-de-toco), seguindo o sistema onde a área de cultivo (roça) era utilizada por 6 a 8 anos com culturas anuais ou bianuais (milho, feijão, cana e mandioca) e depois era deixada para "descansar" por 15 a 20 anos, e se procurava outra área para fazer o cultivo.

No seu modelo mental, os agricultores avaliam que o processo de sucessão e de recuperação do solo na região é muito rápido. Partindo desse pressuposto, acreditam que o sistema de agricultura de pousio teria um caráter de sustentabilidade, uma vez que nunca haveria a necessidade da derrubada de toda a área de mata, além do que as áreas com maior declividade e vales seriam mantidas permanentemente vegetadas.

A agricultura itinerante praticada de forma tradicional pode ser sustentável, como afirma ADAMS (2000). Argumentos para a sustentabilidade do sistema consideram que esse sistema de cultivo promove a rotação de terras, além de implicar baixa incidência de pragas, doenças, e plantas invasoras. Por outro lado, demanda intensiva mão-de-obra e caracteriza-se pelo baixo uso de insumos. Do ponto de vista ecológico, essa agricultura está baseada na ciclagem de nutrientes presentes na biomassa e, por isso mesmo, o estado da vegetação a ser derrubada é fundamental para o sucesso do sistema. A eficiência da vegetação secundária em restaurar os nutrientes é levada em conta pelos agricultores no momento de determinar o tempo de pousio, o que sugere que o relativo curto espaço de tempo de colonização foi suficiente para os agricultores adquirirem o necessário conhecimento local do meio que usam.

Apesar da importância social deste tipo de agricultura, a legislação aplicada ao setor não leva em consideração qualquer aspecto da ecologia do ecossistema, e muito menos aspectos sócio-culturais da sua utilização. Quando, no final dos anos 80, surgiram as novas legislações para regulamentar a utilização dos recursos florestais, acompanhada de sua fiscalização mais rigorosa, uma série de transformações no sistema produtivo e exploratório das propriedades agrícolas da região foi observada. Uma das conseqüências imediatas, relatadas por $60 \%$ dos agricultores entrevistados, foi um aumento considerável da comercialização de madeiras de espécies nativas, uma reação à incerteza sobre o futuro da propriedade dos recursos da floresta em suas propriedades. Essa reação também evidencia a valorização do ecossistema primariamente como produtor de madeira.

Mas, mudanças com profundo impacto no sistema de cultivo, também apontadas como conseqüências das Legislações Ambientais, já foram divisadas pelos agricultores. O ponto que gera a maior polêmica entre agricultores e técnicos das agências ambientais é a autorização de supressão total da vegetação, para fins agrícolas, somente no estádio inicial de regeneração, como dita a Resolução no 04/94 do CONAMA, que também define os parâmetros para o enquadramento da vegetação nesse estádio de regeneração.

O estádio sucessional com as características previstas na Resolução 04/1994 como sendo estádio inicial na região, segundo a observação prática dos agricultores, ocorre até cinco a sete anos após o início do período de pousio, diferindo em muito dos 15 a 25 anos utilizados pelos agricultores. Essa limitação de tempo prevista na legislação é apontada como responsável pelo comprometimento da continuidade do sistema produtivo, uma vez que pressupõe a derrubada da vegetação em um estádio de sucessão no qual as características físico-químicas do solo ainda não estão plenamente recuperadas do desgaste provocado por anos sucessivos de cultivo e, principalmente, o volume de biomassa da vegetação ainda não é suficiente para fornecer a quantidade de nutrientes necessária aos cultivos seguintes. A redução do tempo de pousio já foi apontada, por exemplo, por VANDERMEER \& PERFECTO (1995), como uma das principais causas da falência do sistema de agricultura itinerante.

No Brasil, a questão também já foi levantada por RIBEIRO (2001), que ressalta ser este um ponto que merece destaque como um elemento de desequilíbrio para o sistema da agricultura itinerante, pois, em função da legislação as áreas no início do processo de sucessão florestal, passaram a ser 
cultivadas mais intensamente, rompendo o ciclo e a lógica do sistema que está baseado no período de pousio, com a finalidade de recuperar a fertilidade natural do solo. Neste aspecto, o uso do fogo para a limpeza da área também perde o seu sentido intrínseco ao sistema de agricultura itinerante, que é o de liberar nutrientes para fertilizar o solo.

Em 65\% das propriedades analisadas neste trabalho, houve redução da área de cultivo nos últimos 15 anos. Com relação às mudanças no sistema de cultivo, as principais mudanças apontadas e suas razões foram: (1) redução do tempo de repouso, para evitar que as áreas onde a roça será implantada ultrapassem os limites permitidos pela legislação para derrubada ou corte raso (32\% das propriedades); (2) localização das roças em locais mais distantes e de difícil acesso, com o objetivo de "escondê-las da fiscalização” (23\% das propriedades); (3) redução do número e da "mobilidade” das roças; (4) introdução da adubação dos cultivos, como alternativa à menor fertilidade natural dos solos que tiveram menor tempo de pousio (45\% das propriedades). A maior parte agricultores entrevistados (78\%) acreditam que essas modificações somente trouxeram conseqüências negativas para eles.

Dos agricultores entrevistados, 50\% mostraram-se insatisfeitos com a atividade agrícola e afirmaram que a continuidade na agricultura é também conseqüência da incapacidade de exercer outra atividade, principalmente pela idade.

À primeira vista, parece evidente que a área coberta por formações florestais vem aumentando na região. Do ponto de vista da conservação da natureza, o fato parece alentador. Não é, entretanto, resultado de um planejamento bem feito para atingir tal resultado. Pelo contrário, o resultado está se dando à custa da motivação da população local, que aos poucos perde a sua identidade com a terra. Nos discursos dos agricultores percebe-se claramente a insatisfação em não participarem de programas que objetivem a conservação do patrimônio florestal dentro das suas propriedades. Nesse sentido, o adiamento da adoção de abordagens sistêmicas, como a aprendizagem social (ver, por exemplo ISON (2005) e JIGGINGS \& RÖLING (2002)) em projetos de conservação ambiental e desenvolvimento por parte das agências ambientais oficiais, é inexplicável.

O sistema de pousio e a paisagem

Os dados apresentados na tabela 1 caracterizam a proporção das terras destinadas às diferentes formas de uso, contribuindo para a formação da paisagem atual das propriedades da região. A área média das propriedades foi de 31,2ha, onde as áreas de formações florestais nativas, como a "mata virgem" (termo utilizado pelos agricultores da região em referência às áreas de floresta onde não houve a

Tabela 1 - Uso atual da terra em propriedades agrícolas no município de São Pedro de Alcântara, 2004.

\begin{tabular}{|c|c|c|c|c|c|c|c|c|}
\hline \multirow{4}{*}{ Uso atual } & \multicolumn{8}{|c|}{ Tamanho das propriedades (hectares) } \\
\hline & \multicolumn{2}{|c|}{$<20$} & \multicolumn{2}{|c|}{20 a 50} & \multicolumn{2}{|c|}{$>50$} & \multicolumn{2}{|c|}{ Média geral } \\
\hline & \multicolumn{2}{|c|}{ Área } & \multicolumn{2}{|c|}{ Área } & \multicolumn{2}{|c|}{ Área } & \multicolumn{2}{|c|}{ Área } \\
\hline & (ha) & $(\%)$ & (ha) & $(\%)$ & (ha) & $(\%)$ & (ha) & $(\%)$ \\
\hline \multicolumn{9}{|l|}{ Agropecuario } \\
\hline Pastagem & 3,0 & 21 & 7,0 & 23 & 18,5 & 29 & 7,7 & 25 \\
\hline Roça & 2,0 & 14 & 3,0 & 10 & 11,0 & 17 & 3,8 & 12 \\
\hline Reflorestamento & 0,0 & 0 & 2,0 & 7 & 3,0 & 5 & 1,0 & 3 \\
\hline Capineira & 0,0 & 0 & 1,0 & 3 & 0,8 & 1 & 0,4 & 1 \\
\hline Sub-Total & 5,0 & 35 & 13,0 & 42 & 33,3 & 52 & 12,9 & 41 \\
\hline \multicolumn{9}{|l|}{ Remanescentes Florestais } \\
\hline “Mata virgem” & 1,5 & 10 & 4,1 & 13 & 9,0 & 14 & 4,3 & 14 \\
\hline Capoeirinha & 1,0 & 7 & 2,3 & 8 & 3,0 & 5 & 2,2 & 7 \\
\hline Capoeira & 1,8 & 13 & 2,8 & 9 & 4,0 & 6 & 2,9 & 9 \\
\hline Capoeirão & 2,5 & 17 & 4,2 & 14 & 8,0 & 12 & 4,7 & 15 \\
\hline Arbóreo avançado & 2,0 & 14 & 3,5 & 11 & 5,5 & 9 & 3,5 & 11 \\
\hline Sub-total & 8,8 & 62 & 16,9 & 55 & 29,5 & 47 & 17,6 & 56 \\
\hline Benfeitorias e Estradas & 0,5 & 3 & 0,7 & 2 & 1,3 & 2 & 0,7 & 2 \\
\hline Total & 14,3 & 100 & 28,1 & 100 & 64,1 & 100 & 31,2 & 100 \\
\hline
\end{tabular}

Ciência Rural, v.37, n.3, mai-jun, 2007. 
remoção total da vegetação), a capoeirinha, a capoeira e o capoeirão e o arbóreo avançado representam a maior porcentagem de ocupação (56\%) em relação a área total das propriedades.

As pastagens representam o principal uso da terra depois da floresta, com $25 \%$ da área total das propriedades, e estão localizadas no entorno da sede. O segundo maior uso da terra são as roças (principalmente de cana-de-açúcar), com uma ocupação média de $12 \%$ da área total das propriedades. Essas áreas, em torno de três a seis em cada propriedade, não são contíguas, além de apresentarem diferentes idades desde o início do cultivo. Finalmente, em menores proporções, aparecem as áreas destinadas ao reflorestamento (3\%), ao cultivo de capineira (1\%), basicamente com o uso do capim-elefante (Pennisetum purpureum), e aquelas que dão lugar às benfeitorias e estradas (2\%) (Tabela 1).

Quando se considera a classificação da vegetação em estádios de regeneração como propostos pela Resolução no 04/94 do CONAMA (tendo como referência as espécies indicadoras de cada estádio), têm-se 7\% da área total das propriedades em estádio inicial de regeneração (capoeirinha), 9\% em estádio médio (capoeira), 26\% em estádio avançado (capoeirão e arbóreo avançado) e 14\% de vegetação primária ("mata virgem”).

Quando é analisado o uso da terra em relação ao tamanho das propriedades, observa-se uma tendência de aumento proporcional das áreas destinadas às pastagens em relação à área total das propriedades; essas ocupam $21 \%$ da área das propriedades com menos de 20 ha e $29 \%$ nas propriedades com mais de 50ha. Assim, o oposto é observado em relação à ocupação das terras com áreas de formações florestais nativas em diferentes estádios sucessionais, cujas áreas ocupadas diminuem de $62 \%$ nas propriedades menores que 50ha, para $46 \%$ nas propriedades maiores (Tabela 1).

Essa conformação da paisagem, entretanto, não é estática, uma vez que o sistema de agricultura de roças, por sua característica de rotação, promove uma alternância de usos da terra dentro das propriedades, resultando no que QUEIROZ (1994) configurou como a dinâmica de mosaicos. Esse modelo de uso da terra é altamente favorável à boa disponibilidade e dispersão de propágulos das espécies vegetais dos diferentes estádios em áreas próximas, propiciando assim condições de dinâmica contínua e eficiente do processo de sucessão vegetal (QUEIROZ, 1994). Normalmente, nesse sistema, somente as áreas destinadas a pastagens e as áreas de "mata virgem” não são alteradas.
Os croquis elaborados neste estudo permitiram constatar que as propriedades em sua maioria têm o formato retangular, com disposição da menor dimensão, paralela à estrada que atravessa o município longitudinalmente, resultado da divisão das terras à época da colonização. Na ocupação das terras, podem-se notar três porções distintas das propriedades, sendo a mais próxima à estrada principal composta por áreas de benfeitorias e pastagens. Na porção intermediária da propriedade, encontram-se as áreas de roça e dos estádios sucessionais iniciais. Finalmente, as áreas de floresta em estádio avançado de regeneração e de floresta climáxica ocupam a região mais afastada da sede da propriedade.

Essa configuração diferencia-se da representação esquemática da dinâmica de sucessão apresentada por QUEIROZ (1994), principalmente pelo aumento da proporção das áreas de "Mata Virgem” e Arbóreo Avançado, que, na região estudada neste trabalho, não estão restritas às áreas do alto de encosta, em detrimento das áreas com formações florestais mais jovens. Essas alterações na conformação da paisagem sugerem um menor uso da terra para o cultivo tradicional de roças-de-toco. Essa redução pode ser explicada, em parte, pelas restrições impostas pelas legislações em vigor sobre as possibilidades de uso dos remanescentes florestais. Esta tendência temporal na redução da área de agricultura de pousio também foi observada por ADAMS (2000) em comunidades caiçaras, presentes dentro ou no entorno de unidades de conservação, e também atribuídas a restrições impostas por instrumentos legais.

Entretanto, há que se atentar para o fato de que outros fatores podem estar contribuindo para a diminuição das áreas usadas para cultivos na região, como o aumento da idade média dos agricultores e a migração para centros urbanos. Estimar a extensão do impacto da legislação florestal sobre a utilização das terras para cultivos é tarefa que ainda está por ser realizada.

Os resultados expostos na tabela 1 apresentam a ocupação atual do solo representando um corte temporal do uso das terras. Entretanto, quando estas informações são complementadas com os dados coletados nas entrevistas e com os levantamentos de campo, permitem estimar a área ocupada pelas culturas e a área necessária para assegurar a continuidade da agricultura de pousio, avaliando a viabilidade espacial e temporal do sistema dentro das características das propriedades na região de São Pedro de Alcântara.

Para tanto, são necessárias algumas considerações: a) áreas de "mata virgem” e arbóreo 
avançado serão consideradas como áreas “indisponíveis para supressão", dentro do sistema de cultivo de roças. Estão contempladas na categoria “passíveis de supressão” as áreas pertencentes aos estádios sucessionais de capoeirinha, capoeira e capoeirão; b) tempo de utilização de cada roça de seis anos, sendo mantida a quantidade de roças atualmente utilizadas (três a seis), com uma área média de 0,7ha; c) tempo de pousio de aproximadamente 20 anos.

Dentro desta perspectiva, as propriedades que possuem até 20ha necessitariam suprimir o equivalente a uma área de uma roça a cada dois anos, ou seja, após 20 anos seria suprimida uma área total de 7,0ha. Esta necessidade é atendida somando-se as áreas passíveis de supressão, ficando assegurado uma área com cobertura florestal constante, que representa $24 \%$ do total da área das propriedades. Quando se consideram as propriedades que possuem entre $20 \mathrm{e}$ 50ha (média das propriedades da região), a necessidade de supressão da vegetação é atendida com as áreas passíveis de supressão e, novamente, fica-se resguardando a área com cobertura florestal em $24 \%$ (Tabela 2).

Para as propriedades com mais de 50ha, a necessidade de supressão da vegetação é de 30ha no período de 20 anos. Essa necessidade fica abaixo do total de área “disponível” (26,0ha). Neste caso, as áreas de "mata virgem” e arbóreo avançado somam 14,5ha, representando 23\% da área total da propriedade (Tabela 2).

Entretanto, o excesso na redução do período de pousio ou no aumento do tempo de plantio, situações de ocorrência eminente quando há restrições legais de supressão, podem colocar este equilíbrio em risco. Os resultados obtidos indicam que o sistema de agricultura de pousio deve ser analisado como um todo, considerando que não é a terra em si que os agricultores exploram, mas o complexo vegetação-solo que se desenvolveu na área.

\section{CONCLUSÕES}

A cobertura florestal na região estudada está aumentando, assim como a idade média dos blocos de formações florestais. A imposição de restrições para a supressão da vegetação em estádio de regeneração mais avançado que o inicial é reconhecida pelos agricultores como um impedimento para a continuidade da roça-de-toco como praticada tradicionalmente, fato que contribui substancialmente para o aumento da cobertura florestal. As áreas com formação florestal representam 49\% da área das propriedades e incluem as áreas de preservação permanente e de reserva legal, além das áreas em estádio médio e avançado de regeneração. As áreas de uso agrícola permanente, principalmente pastagens, representam 29\% da área total das propriedades. As áreas cobertas com vegetação secundária e agrícola passíveis de uso, somadas, compõem 19\% da área das propriedades. Os resultados permitiram a fundamentação da viabilidade espacial, ao longo do tempo, do sistema de cultivo de pousio nas propriedades agrícolas do município de São Pedro de Alcântara. O sistema também mostra-se eficiente do ponto de vista produtivo, permitindo o aproveitando do momento de maior crescimento, em termos de biomassa, das florestas secundárias (até 30 anos).

\section{AGRADECIMENTOS}

Os autores agradecem o apoio recebido dos pesquisadores e bolsistas do Núcleo de Pesquisas em Florestas Tropicais da Universidade Federal de Santa Catarina para a realização deste trabalho.

Tabela 2 - Simulação da viabilidade espacial e temporal do sistema de roça-de-toco no município de São Pedro de Alcântara, 2004.

\begin{tabular}{|c|c|c|c|c|c|c|}
\hline \multirow{3}{*}{ Simulação do uso da terra } & \multicolumn{6}{|c|}{ Tamanho das propriedades (hectares) } \\
\hline & \multicolumn{2}{|c|}{$<20$} & \multicolumn{2}{|c|}{20 a 50} & \multicolumn{2}{|c|}{$>50$} \\
\hline & (ha) & $(\%)$ & (ha) & $(\%)$ & (ha) & $(\%)$ \\
\hline $\begin{array}{l}\text { Necessidade de supressão } \\
\text { (20 anos de ciclo) }\end{array}$ & 7,0 & 49 & 10,0 & 36 & 30,0 & 48 \\
\hline $\begin{array}{l}\text { Passível de supressão } \\
\text { (capoeirinha + capoeira + capoeirão + roça) }\end{array}$ & 7,3 & 51 & 12,3 & 41 & 26,0 & 40 \\
\hline $\begin{array}{l}\text { Indisponível para supressão } \\
\text { (mata virgem + arbóreo avançado) }\end{array}$ & 3,5 & 24 & 7,6 & 24 & 14,5 & 23 \\
\hline
\end{tabular}

Ciência Rural, v.37, n.3, mai-jun, 2007. 


\section{REFERÊNCIAS}

ADAMS, C. Caiçaras na Mata Atlântica: pesquisa científica versus planejamento e gestão ambiental. São Paulo: Amablume/FAPESP, 2000. 337p.

COOMER, O.T. et al. Tropical forests and shifting cultivation: secondary forest fallow dynamics among traditional farmers of the Peruvian Amazon. Ecological Economics, v.32, 109124, 2000

EMBRAPA. Centro nacional de Pesquisa de Solos (Rio de Janeiro-RJ). Sistema brasileiro de classificação de solos. Brasília: Embrapa. Produção de Informação; Rio de Janeiro: Embrapa Solos, 1999. 412p.

FUNDAÇÃO SOS MATA ATLÂNTICA E INSTITUTO NACIONAL DE PESQUISAS ESPACIAIS, Instituto Sócio Ambiental. Atlas da evolução dos remanescentes florestais e ecossistemas associados no domínio da mata atlântica no período de 1995-2000. São Paulo, 2000. 55p.

IDE, B.Y. et al. Zoneamento agroclimático do Estado de Santa Catarina, 2a Etapa. Florianópolis: EMPASC, 1980. 106p.

ISON, R. Traditions of understanding: language, dialogue and experience. In: KEEN, M. et al. Social learning in environmental management: towards a sustainable future. London: Earthscan, 2005. p.22-40.

JIGGINGS, J.; RÖLING, N. Adaptive Management: potential and limitations for ecological governance of forests in a context of normative pluriformity. In: OGLETHORPE, J.A.E. (Ed). Adaptive management: from theory to practice. Gland: IUCN, 2002. p.93-104.

KLEIN, R.M. Ecologia da flora e vegetação do Vale do Itajaí. Sellowia, v.32, n.32, p.164-369, 1980.

KLEIN, R.M. et al. Vegetação. In: SANTA CATARINA. Atlas de Santa Catarina. Santa Catarina. Florianópolis: Gabinete do planejamento e Coordenação Geral de Santa Catarina, 1986. p.35-36.

MARTINS, P.S. Dinâmica evolutiva em roças de caboclos amazônicos. In: VIEIRA, I.C.G. et al. Diversidade biológica e cultural da Amazônia. Belém: Museu Emilio Goeldi, 2001. p.369-384

MINAYO, M.C.S. O desafio do conhecimento: pesquisa qualitativa em saúde. 2.ed. São Paulo; Rio de Janeiro: Hucitec-Abrasco, 1993. 269p.
OLIVEIRA, R.R. Ação antrópica e resultantes sobre a estrutura e composição da Mata Atlântica na Ilha Grande, RJ. Rodriguésia, v.53, n.82, p.33-58, 2002.

PERONI, N.; MARTINS, P.S. Influência da dinâmica agrícola itinerante na geração de diversidade de etnovariedades cultivadas vegetativamente. Interciência, v.25, n.1, p.22-29, 2000.

PREFEITURA MUNICIPAL DE SÃO PEDRO DE ALCÂNTARA. Informações Básicas. Acesso em 25 de ago. de 2003. Disponível na internet em: http://www.pmspa.sc.gov.br.

QUEIROZ, M.H. Approche phytoécologoque et dynamique des formations végetales secondaires développées après abandon dês activités agricoles, dans lê domaine de la fôret ombrophile dense de versant (Fôret Atlantique) à Santa Catarina - Brésil. 1994. 251f. Tese (Doutorado em Ciências Florestais) - École Nationale du Génie Rural, des Eaux et des Forêts.

RIBEIRO, R.J. Desenvolvimento participativo de critérios para o licenciamento de manejo tradicional de capoeiras no Vale do Ribeira. (Um trabalho proposto pelo Projeto Iguape-Juréia (PROTER/REBRAF) e elaborado pela Atlântica Consultoria Agroambiental). Registro, 2001. (não publicado).

SALDARRIAGA, J.G. et al. Long-term chronosequence of foret succession in the upper Rio Negro of Colombia and Venezuela. Journal of Ecology, v.76, p.938-958, 1998.

SANTA CATARINA (Estado). Levantamento de reconhecimento de solos do Estado de Santa Catarina. (Convênio Sudesul-UFSM, SAG). Santa Maria: UFSM, 1973. 2v. 494p.

SIMINSKI, A. Formações florestais secundárias como recurso para o desenvolvimento rural e a conservação ambiental no litoral de Santa Catarina. 2004. $117 \mathrm{f}$. Dissertação (Mestrado em Recursos Genéticos Vegetais) Universidade Federal de Santa Catarina.

ULH, C. Factors controlling succession following slash-andburn agriculture in amazonia. Journal of Ecology, v.75, p.377407, 1987.

VANDERMEER, J.; PERFECTO, I. Breakfast of biodiversity: the truth about rain forest destruction. Oakland: Food First, 1995. 192p.

VELOSO, H.P. et al. Classificação da vegetação brasileira, adaptada a um sistema universal. Rio de Janeiro: IBGE, Departamento de Recursos Naturais e Estudos Ambientais, 1991. $124 p$. 